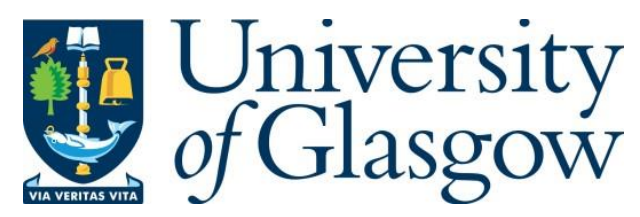

Dervin, S., Ganguly, P. and Dahiya, R. (2021) Disposable electrochemical sensor using graphene oxide - chitosan modified carbon-based electrodes for the detection of tyrosine. IEEE Sensors Journal, (doi: 10.1109/JSEN.2021.3073287).

There may be differences between this version and the published version. You are advised to consult the publisher's version if you wish to cite from it.

http://eprints.gla.ac.uk/237871/

Deposited on: 31 March 2021

Enlighten - Research publications by members of the University of Glasgow http://eprints.gla.ac.uk 


\title{
Disposable electrochemical sensor using Graphene oxide - chitosan modified carbon-based electrodes for the detection of tyrosine
}

\author{
Saoirse Dervin, Student Member, IEEE, Priyanka Ganguly, and Ravinder Dahiya Fellow, IEEE
}

\begin{abstract}
Despite the many recent advances in disposable and wearable sensing technologies for point of care testing (POCT), few affordable, flexible, and disposable sensors are available for the detection of tyrosine (Tyr), a valuable biomarker for metabolic and neurodegenerative diseases. In this regard, the disposable screen-printed electrodes on flexible substrates are attractive. However, current screenprinted approaches for the detection of Tyr use rigid ceramic substrates, expensive metal nanoparticle conductive inks and stiff metal or metal oxide-based sensitive materials, that are not suitable for single-use disposable or wearable POCT devices. To address these challenges, this work presents a flexible and disposable electrochemical sensor using graphene oxide - chitosan (GO-CS) modified carbon-based electrodes for the detection of Tyr. The affordable and easy to fabricate sensor consists of a three-carbon electrode system screen printed on a flexible, low-cost polyvinyl chloride (PVC)

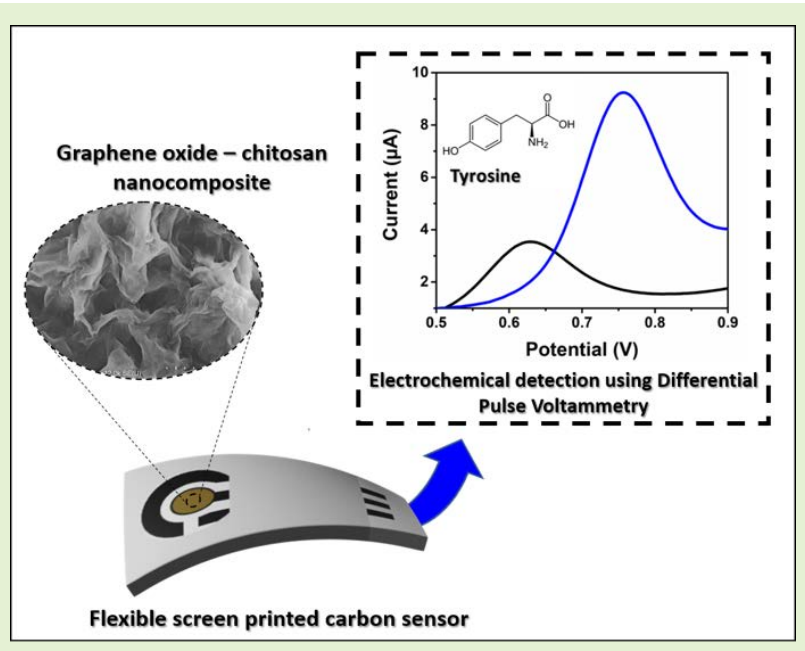
substrate. GO and CS were chosen as the sensitive nanocomposite due to their natural abundance and excellent electrochemical sensing properties. Quantitative determination of Tyr using DPV revealed a linear proportional response between 1 and $100 \mu \mathrm{M}$, with a correlation coefficient of 0.9993 . The GO-CS-screen-printed carbon sensor (SPCS) also offers a linear range detection limit of $5.86 \mu \mathrm{M}$, and excellent sensitivity $\left(0.0846 \mu \mathrm{A}^{-1} \mathrm{M}^{-1}\right)$ and repeatability (RSD $=4.02 \%$ ). The GO-CS-SPCS thereby provides a promising platform for the active sensing elements of single-use, disposable, and wearable POCT devices suitable for early diagnosis and monitoring of metabolic or neurodegenerative diseases or nutritional management.
\end{abstract}

Index Terms- Wearable sensors; Tyrosine; electrochemical sensing; carbon-reference electrode; Disposable Sensor

\section{INTRODUCTION}

Point of care testing (POCT) of nutrients and metabolites present in the human body, and their concentrations in biofluids, forms an essential basis for health or clinical risk assessments, fast disease diagnosis and prognosis, and for the monitoring of therapeutic outcomes and the status of health conditions [4, 5]. For example, tyrosine (Tyr) is a conditionally essential amino acid that serves as a building block for several vital nutritional proteins $[8,9]$. Tyr is also critical to the synthesis of a variety of neurotransmitters and hormones, including adrenaline, norepinephrine, dopamine, epinephrine, catecholamine, thyroxin, melanin and oestrogen $[1,12]$. Abnormal Tyr concentrations could, therefore,

An earlier version of this paper was presented at the IEEE FLEPS 2020 Conference and was published in its Proceedings https://doi.org/10.1109/FLEPS49123.2020.9239514

This work was supported in part by the European Commission through AQUASENSE (H2020-MSCA-ITN-2018-813680)

Saoirse Dervin, Ammara Ejaz, Priyanka Ganguly and Prof. Ravinder Dahiya (e-mail: Ravinder.Dahiya@glasgow.ac.uk). are with the Bendable Electronics and Sensing Technologies (BEST) Group, James Watt School of Engineering, University of Glasgow, UK induce a range of congenital or neurodegenerative diseases, including tyrosinemia, albinism, alkaptonuria, phenylketonuria, hypochondria, dementia, hypothyroidism atherosclerosis, eating disorders and lung disease [13-16]. Along with other amino acids, Tyr also plays an important role in the development of Alzheimer's and Parkinson's disease [18]. Thus, point of care (POC) measurement of this valuable aromatic biomarker present an important opportunity for early diagnosis and monitoring of metabolic or neurodegenerative diseases $[1,18,20]$.

Considering this, POC sensing tools that are suitable for onsite measurements, where affordable, user-friendly, and disposable devices are preferred, are in critical demand. Relatively simple fabrication processes, fast and label-free detection, portability, the possibility of miniaturization, high sensitivity and low limits of detection, etc., are central to the development of these POCT devices [21, 22]. Flexibility, and biocompatibility are also crucial factors for the development of wearable systems with conformable form factors that interface with human skin or the curvature of soft biological materials [23-25]. 
TABLE I

PERFORMANCE COMPARISON OF SENSORS FOR THE DETECTION OF TYROSINE

\begin{tabular}{|c|c|c|c|c|c|}
\hline Sensor & Detection limit & Linear range & $\begin{array}{l}\text { Compliant with } \\
\text { wearable POCT }\end{array}$ & $\begin{array}{l}\text { Easy to } \\
\text { fabricate }\end{array}$ & REF \\
\hline Laser-engraved graphene-based chemical sensor & $3.6 \mu \mathrm{M}$ & $50-500 \mu \mathrm{M}$ & $\checkmark$ & $\mathrm{X}$ & [1] \\
\hline $\begin{array}{l}\text { Flexible CVD graphene platform electrode modified } \\
\text { with l-aspartic acid }\end{array}$ & $0.31 \mu \mathrm{M}$ & $0.1-93.9 \mu \mathrm{M}$ & $\checkmark$ & $\mathrm{X}$ & [2] \\
\hline $\begin{array}{l}\text { Al-CuSe-nanoparticles (NPs) modified screen-printed } \\
\text { carbon electrode (SPCE) }\end{array}$ & $0.04 \mu \mathrm{M}$ & $0.15-10 \mu \mathrm{M}$ & $\mathrm{X}$ & $\checkmark$ & [3] \\
\hline $\begin{array}{l}\text { Exfoliated } 2 \mathrm{D}-\mathrm{MoS} 2 \text { nanosheets on carbon and } \mathrm{Au} \\
\text { screen printed electrode (SPE) }\end{array}$ & $\begin{array}{c}31.23 \mu \mathrm{M} \\
0.5 \mu \mathrm{M}\end{array}$ & $0-200 \mu \mathrm{M}$ & $\mathrm{X}$ & $\checkmark$ & [6] \\
\hline 2D-MoS2 nanosheets modified SPCE & $0.5 \mu \mathrm{M}$ & $1-500 \mu \mathrm{M}$ & $\mathrm{X}$ & $\checkmark$ & [7] \\
\hline $\begin{array}{l}\text { Tetrathiafulvalene-tetracyanoquinodimethane (TTF- } \\
\text { TCNQ)/ionic liquid gel modified SPE }\end{array}$ & $0.04 \mathrm{pM}$ & $0.1-20 \mathrm{pM}$ & $\mathrm{X}$ & $\checkmark$ & [10] \\
\hline $\mathrm{NiO} \mathrm{NP}$ modified graphite SPE & $0.1 \mu \mathrm{M}$ & $0.15-450 \mu \mathrm{M}$ & $\mathrm{X}$ & $\checkmark$ & [11] \\
\hline $\begin{array}{l}\text { MWCNTs-doped Poly(glycine)/Poly(acrylic acid) } \\
\text { conducting polymer modified SPE }\end{array}$ & $0.13 \mu \mathrm{M}$ & $\begin{array}{c}0.25-120 \mu \mathrm{M} \\
0.4-150 \mu \mathrm{M}\end{array}$ & $\mathrm{X}$ & $\checkmark$ & [17] \\
\hline $\mathrm{GO} / \mathrm{ZnO}$ modified graphite SPE & $0.34 \mu \mathrm{M}$ & $1-800 \mu \mathrm{M}$ & $\mathrm{X}$ & $\checkmark$ & [19] \\
\hline $\begin{array}{l}\mathrm{CuO} / \beta \text {-cyclodextrin }(\beta-\mathrm{CD}) / \mathrm{Nafion} \quad(\mathrm{Nf}) \text { modified } \\
\text { glassy carbon electrode }(\mathrm{GCE})\end{array}$ & $0.0082 \mu \mathrm{M}$ & 0.01 to $100 \mu \mathrm{M}$ & $\mathrm{X}$ & $\checkmark$ & [26] \\
\hline $\begin{array}{l}\text { ErVO4/MnWO4 modified carbon paste electrode } \\
\text { (CPE) }\end{array}$ & $7.7 \mathrm{nM}$ & $0.08-400 \mu \mathrm{M}$ & $\mathrm{X}$ & $\checkmark$ & [34] \\
\hline 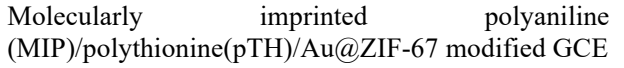 & $0.0079 \mu \mathrm{M}$ & $0.01-4 \mu \mathrm{M}$ & $\mathrm{X}$ & $\checkmark$ & [35] \\
\hline rGO-Cu modified graphite pencil electrode & $0.01 \mu \mathrm{M}$ & $5.5-72 \mu \mathrm{M}$ & $\mathrm{X}$ & $\checkmark$ & [36] \\
\hline Fe3O4 NP modified CPE & $50.0 \mathrm{nM}$ & $0.4-270 \mu \mathrm{M}$ & $\mathrm{X}$ & $\checkmark$ & [37] \\
\hline Ultrathin $\mathrm{g}-\mathrm{C} 3 \mathrm{~N} 4 / \mathrm{Ag}$ modified GCE & $0.14 \mu \mathrm{M}$ & $1-150 \mu \mathrm{M}$ & $\mathrm{X}$ & $\checkmark$ & [38] \\
\hline Flexible GO-CS modified SPCS & $5.86 \mu \mathrm{M}$ & 1 to $100 \mu \mathrm{M}$ & $\checkmark$ & $\checkmark$ & $\begin{array}{l}\text { This } \\
\text { work }\end{array}$ \\
\hline
\end{tabular}

In this regard, single-use disposable or wearable electrochemical sensors that can detect biochemical metabolites in biological fluids, such as blood, urine, saliva, interstitial fluid, and sweat have opened new opportunities for POCT [27-32]. Despite the many recent advances in disposable and wearable sensing technologies for POCT, current systems are primarily focused on a limited number of metabolites, and few low-cost, flexible, and disposable sensors are available for Tyr POCT [1, 2, 33]. Most of the current approaches use complex or time-consuming fabrication processes that require sophisticated instrumentation, or solid electrodes, such as glassy carbon electrodes (GCEs), carbon paste electrodes (CPEs) or graphite pencil electrodes, etc., that are not suitable for single-use disposable systems (Table 1) [1, 2, 26, 33-38]. As an alternative, disposable screen-printed electrodes (SPEs) offer fast, affordable, and widespread testing at the point of care, without the need for skilled analysts or complicated measuring equipment [39-41]. Since SPEs are customizable, they can also be modified using metals, nanomaterials, polymers, conducting polymers, carbon-based materials, enzymes, mediators, or complexing agents, or by incorporating these different materials in the ink composition before printing to enhance performance, stability and versatility $[42,43]$. Furthermore, by using flexible substrates, screen printed electrodes can be easily integrated into a range of different sensing technologies - from the worlds of sports and fashion to automotive and healthcare [44]. Be this as it may, current screen-printing approaches for the detection of Tyr use rigid ceramic substrates, expensive metal nanoparticle conductive inks and stiff metal or metal oxidebased sensitive materials, that are neither sustainable nor suitable for single-use disposable or wearable sensors (Table 1) $[3,6,7,10,11,17,19]$.
By taking advantage of easy-to-use fabrication methods, flexible substrates suitable for wearable systems, and lowcost, disposable, and biocompatible materials, this work thus presents a simple method for the detection of Tyr, that could open new opportunities for POCT and self-health management [27-30]. This paper extends our preliminary results presented in IEEE FLEPS 2020 [45]. Previously, a low-cost, disposable GO-CS screen printed carbon electrode (SPCE) (GO-CS-SPCE) was presented for the electrochemical detection of tyrosine. GO and CS were chosen for the sensitive film due to their natural abundance, excellent electrochemical sensing properties, good chemical stability, flexibility, and excellent film-forming capability. Furthermore, the affordable, biocompatible, eco-friendly, and biodegradable nature of this nanocomposite, as highlighted in our previous work, make GO and CS ideal candidates for affordable, disposable devices suitable for wearable POCT devices [5, 22, 46, 47]. For the electrochemical detection of Tyr, an $\mathrm{Ag} / \mathrm{AgCl}$ (3.0MNaCl solution) reference electrode and a $\mathrm{Pt}$ wire counter electrode were used, in addition to the GO-CS-SPCE. The current work, however, presents a threecarbon electrode system, including a carbon working (WE), counter (CE) and reference electrode (RE), screen printed on a flexible polyvinyl chloride (PVC) substrate. The surface of the carbon WE was modified using the GO-CS nanocomposite. By using a carbon ink for the WE, $\mathrm{CE}$ and $\mathrm{RE}$ it is possible to reduce costs and stability issues associated with typical Ag-based REs, for example, incompatibility with some species that are commonly present in biological fluids, such as chloride [48]. The efficiency of the GO-CS-screen-printed carbon sensor (SPCS) (SPCS) for the electrochemical detection of Tyr was investigated using cyclic voltammetry $(\mathrm{CV})$ and differential pulse voltammetry (DPV). 
The rest of this paper is organised as follows: Section II presents the experimental details related to both the SPCS and GO-CS-SPCS. The results are shown in Section III, and key outcomes are summarized in Section IV.

\section{EXPERIMENTAL SECTION}

\section{A. Reagents and apparatus}

Graphene oxide (GO) (highly concentrated single-layer graphene oxide solution, $5 \mathrm{~g} / \mathrm{l}$ ) was purchased from Graphene Supermarket. Chitosan (low molecular weight), L-tyrosine, acetic acid $\left(\mathrm{CH}_{3} \mathrm{COOH}\right)$, hydrochloric acid $(\mathrm{HCl})$, aluminium oxide $\left(\mathrm{Al}_{2} \mathrm{O}_{3}\right)$ and methanol $\left(\mathrm{CH}_{3} \mathrm{OH}\right)$ were purchased from Sigma-Aldrich, UK. All reagents were of analytical grade and used without further purification. Conductive carbon paste and insulative polyurethane varnish were purchased from Sun Chemicals and Blackfriar, respectively. High purity nitrogen $\left(\mathrm{N}_{2}\right)$ gas was used for PBS deoxygenation.

\section{B. Preparation of GO-CS}

A chitosan solution $(1 \%(\mathrm{w} / \mathrm{v}))$ was first prepared by dissolving chitosan powder in an acetic acid aqueous solution (1\%). The mixture was then stirred until a homogenous solution was obtained, typically overnight. A specified volume of GO solution was subsequently added to the dissolved chitosan solution. The mixture was shaken vigorously before sonicating for $5 \mathrm{~h}$ to obtain a homogenous GO-CS solution (Figure 1).

\section{Sensor preparation and modification}

A three-carbon electrode system was first prepared by applying a commercial carbon paste onto a PVC substrate using a conventional screen-printing process. The SPCS consisted of a circular working electrode (WE), with 10-mm diameter and a partial circle of a counter (CE) and a reference electrode (RE) (Figure 1). After printing, the SPCS was cured at $80^{\circ} \mathrm{C}$ for 30 minutes. A Cu wire was then fixed to the WE, CE and RE, respectively. Commercial carbon paste was used to provide a conductive interconnect that was protected by a printed layer of insulative polyurethane. To further modify the surface of the SPCS, $10 \mu \mathrm{L}$ GO-CS solution was drop cast onto the exposed surface of the WE before drying in an oven at $60^{\circ} \mathrm{C}$ for 30 minutes.

\section{Structural and morphological characterisation}

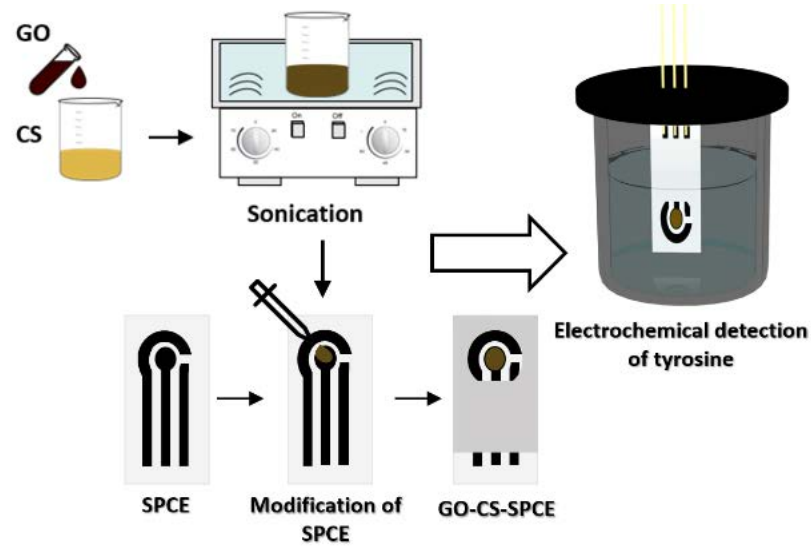

Figure. 1. Schematic representation of sensor preparation and modification
The surface morphology of the GO-CS-SPCS was examined using a Nikon Eclipse LV100ND microscope connected with Leica MC170HD camera and a Hitachi SU8240 fieldemission scanning electron microscope (FESEM). The crystallinity of the GO-CS sensitive nanocomposite was examined by X-ray diffraction (XRD) using a P'Analytical X'Pert with $\mathrm{Cu} \mathrm{K \alpha}(\lambda=1.541 \AA)$.

\section{E. Electrochemical measurements}

A standard analyte stock solution was first prepared by dissolving $1 \mathrm{mM}$ Tyr in a $1 \mathrm{M}$ aqueous $\mathrm{HCl}$ solution. Working solutions containing different Tyr concentrations $(1-500 \mu \mathrm{M})$ were prepared by subsequently diluting the stock solution with $1 \mathrm{M}$ aqueous $\mathrm{HCl}$ before electrochemical measurements. CV and DPV were performed using a Metrohm Autolab (PGSTAT302N) electrochemical workstation.

\section{RESULTS AND DISCUSSION}

\section{A. Structural and morphological characterisation}

Optical imaging and scanning electron microscopy (SEM) were used to examine the surface morphology of the GO-CSSPCS. As shown in Figure 2a and 2b, the GO-CS-SPCS demonstrated a denser carbon network and higher surface roughness than the SPCS. SEM images (Figure $2 \mathrm{~d}$ and 2e) also show a rough and homogeneous interconnected lamellar structure. Due to physical crosslinking and chain entangling, the fully exfoliated GO nanosheets are well dispersed throughout the chitosan matrix without any aggregation. The crystallinity of the GO-CS sensitive nanocomposite film was investigated using XRD, as shown in Figure 3. The XRD patterns of neat GO and CS are also shown in Figure 3. The XRD pattern of neat GO exhibited a characteristic basal

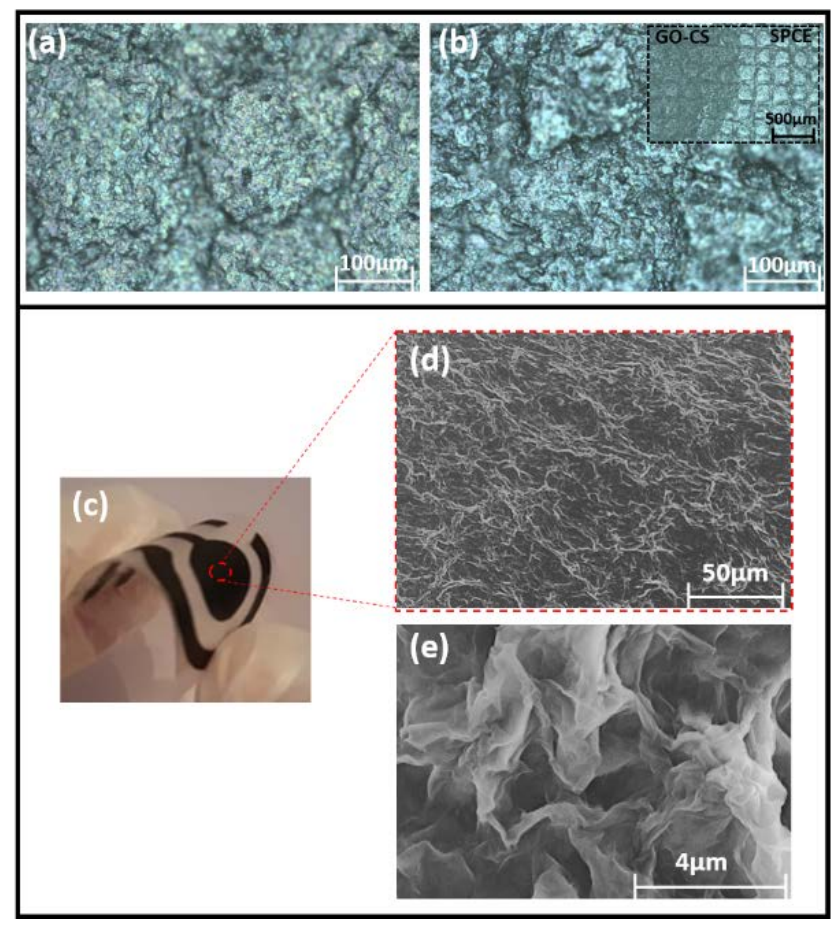

Figure. 2. Optical microscope images of (a) SPCS and (b) GO-CSSPCS, (c) Photographic image of flexible GO-CS-SPCS and (d) SEM image of GO-CS-SPCS. 


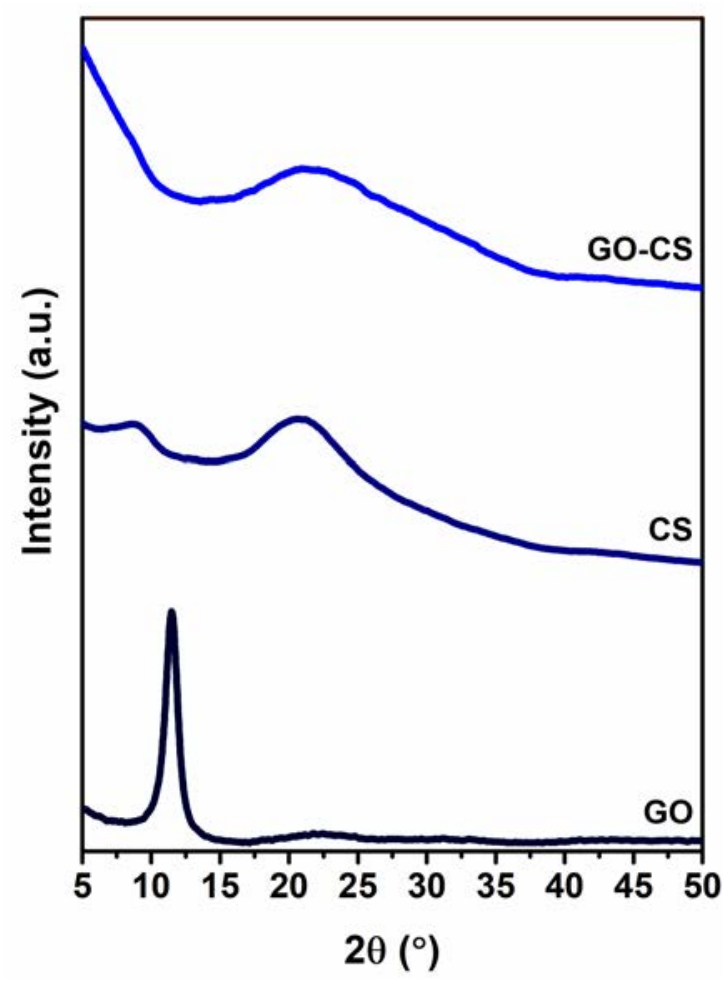

Figure. 3. XRD pattern of GO, CS and GO-CS

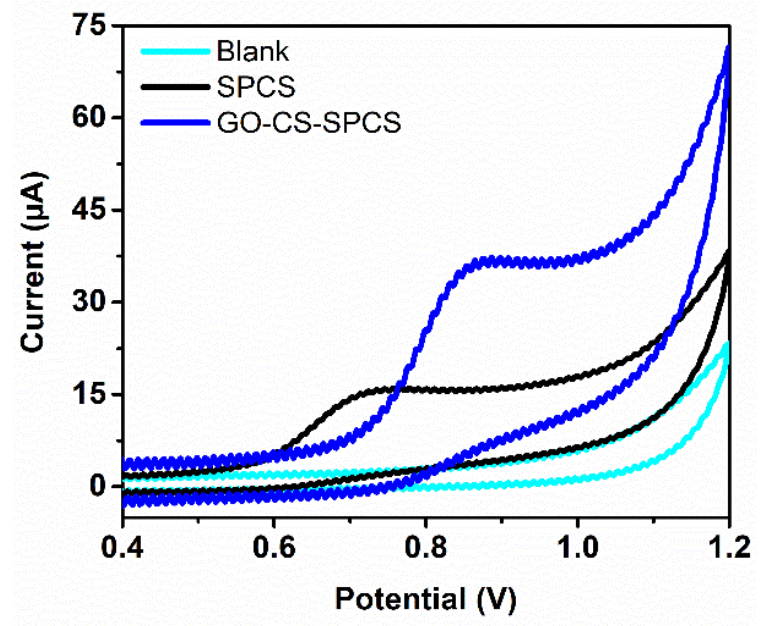

Figure. 4. CV measurements with a scan rate of $100 \mathrm{mV} \mathrm{s}^{-1}$ in the absence and presence of $100 \mu \mathrm{M}$ Tyr in $0.1 \mathrm{M}$ PBS (pH 7) at the surface of both the SPCS and GO-CS-SPCS.

reflection (001) at $2 \theta=11.5^{\circ}$ [49]. Neat chitosan showed two weak, broad diffraction peaks at $2 \theta=8.7^{\circ}$ and $20.7^{\circ}$. The peak centred at $8.7^{\circ}$ corresponds to a hydrated crystalline structure, whereas the broadened peak at $20.7^{\circ}$ is attributed to the existence of an amorphous structure [50]. GO-CS demonstrated a similar XRD pattern to that of pure CS, showing only one broad diffraction peak at $2 \theta=21.5^{\circ}$, which corresponds to the amorphous state of CS. The absence of a characteristic GO peak suggests that the regular and periodic structure of GO became more disordered due to the formation of a randomly oriented 3D network [51]. The incorporation of GO within the biopolymer matrix had little effect on the crystalline properties of $\mathrm{CS}$, indicating that
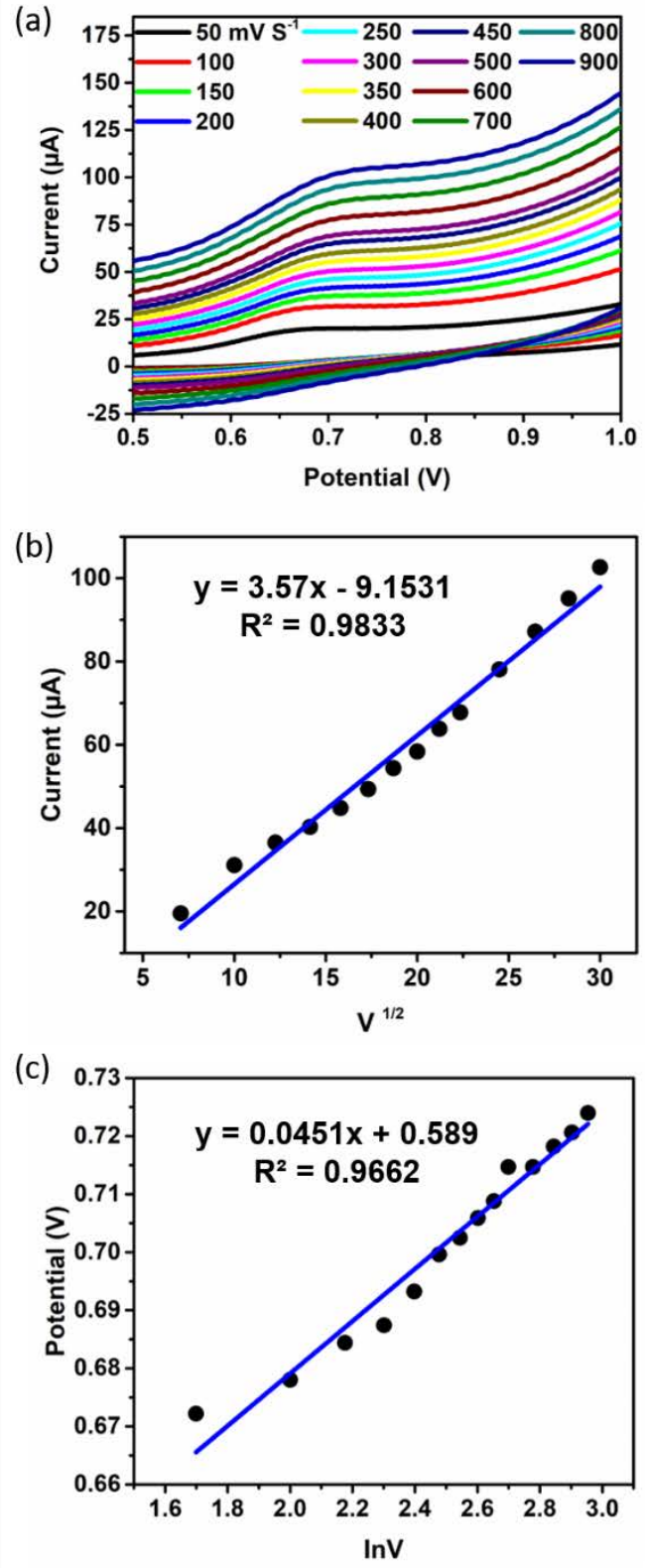

Figure. 5. (a) CV measurements of $100 \mu \mathrm{M}$ Tyr in $0.1 \mathrm{M}$ PBS (pH 7) at the surface of the GO-CS-SPCS with scan rates of 50, 100, 150, 200, 250, 300, 350, 400, 450, 500,600, 700, 800 and $900 \mathrm{mV} \mathrm{s}^{-1}$, resp., (b) plot of peak current $\left(\mathrm{I}_{\mathrm{p}}\right)$ vs. square root of scan rate $\left(v^{1 / 2}\right)$ and $(c)$ plot of peak potentials $\left(E_{p}\right)$ vs. $\log$ of scan rate $(\ln v)$.

there were mainly physical interactions between GO and CS $[52,53]$.

\section{B. Electrochemical detection of Tyr}

The electrochemical detection of $100 \mu \mathrm{M}$ Tyr in $0.1 \mathrm{M}$ phosphate buffer solution (PBS) $(\mathrm{pH} 7)$ was first examined at the surface of the SPCS and GO-CS-SPCS, respectively, using CV measurements with a scan rate of $100 \mathrm{mV} \mathrm{s}^{-1}$. Before this, CV measurements were recorded in blank PBS solutions $(\mathrm{pH} 7)$ to ensure no redox peaks were observed (Figure 4). When the potential was scanned from $400 \mathrm{mV}$ to $1200 \mathrm{mV}$ in the presence of $100 \mu \mathrm{M}$ Tyr, a single anodic peak was observed at the surface of both the SPCS and GO-CS- 
SPCS, indicating that the oxidation reaction occurring at the surface of the bare and modified three-carbon electrode systems is irreversible. The observed oxidation peak potential $\left(E_{p}\right)$ of Tyr at the surface of the SPCS is $750 \mathrm{mV}$. In the case of GO-CS-SPCS, however, the $\mathrm{E}_{\mathrm{p}}$ of Tyr shifted to a more positive potential $(860 \mathrm{mV})$, along with slightly higher currents. This shift in potential is likely due to strong electrostatic attraction between the negative surface hydroxyl groups $\left(\mathrm{OH}^{-}\right)$of $\mathrm{GO}$ and the cationic groups $\left(\mathrm{NH}_{3}{ }^{+}\right)$of CS.[54] As well as the increased dispersion stability of GO nanosheets when using CS as a fixative or dispersing agent. Furthermore, the aromatic Tyr structure may also facilitate, $\pi-\pi$ stacking between $\mathrm{GO}$ and Tyr [8].

\section{Effect of Scan Rate}

The effect of potential scan rates on the electrochemical oxidation current of $100 \mu \mathrm{M}$ Tyr in $0.1 \mathrm{M}$ PBS (pH 7) has been studied at the surface of the GO-CS-SPCS using CV measurements, with different scan rates ranging from 50-900 $\mathrm{mV} \mathrm{s}^{-1}$. Due to the electric double layer (EDL) mechanism, fast charge/discharge processes, and higher ohmic resistance, the oxidation peak current $\left(\mathrm{I}_{\mathrm{p}}\right)$ of Tyr increases as the potential scan rate increases (Figure 5a). The oxidation peak also shifts from $670 \mathrm{mV}$ to a more positive potential of 710 $\mathrm{mV}$, typical of irreversible surface controlled electrochemical processes [36]. A linear relationship between the $I_{p}$ and the
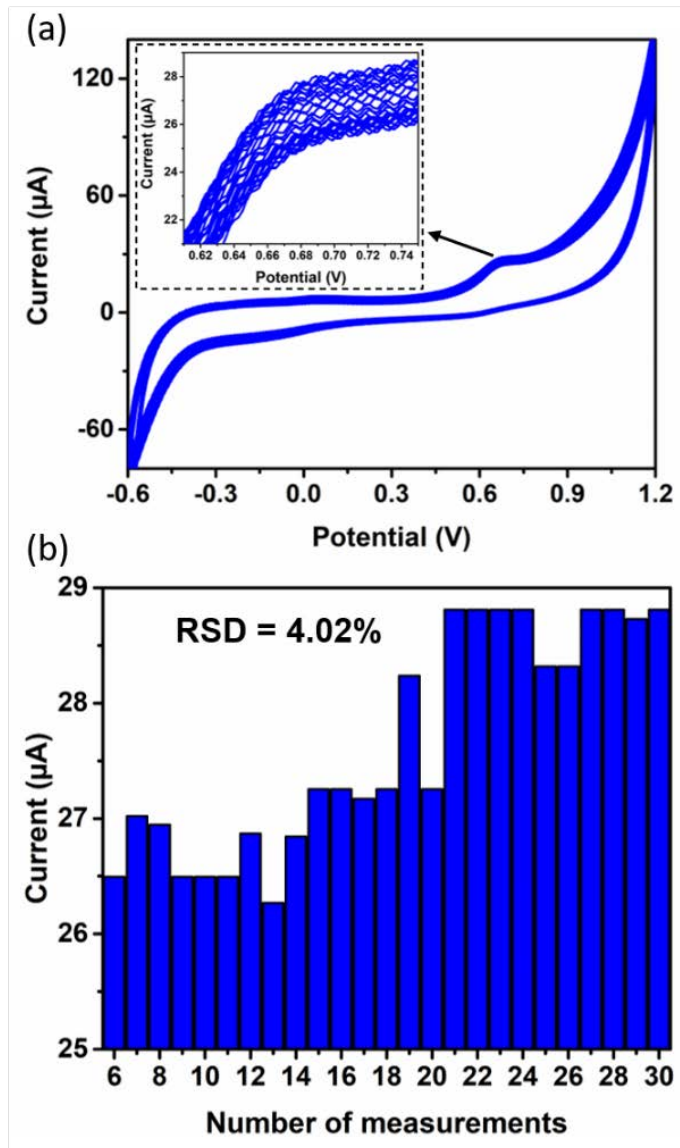

Figure. 6. (a) 30 successive $\mathrm{CV}$ measurements, with a scan rate of $100 \mathrm{mV} \mathrm{s}^{-1}$ in the presence of $100 \mu \mathrm{M}$ Tyr in $0.1 \mathrm{M} \mathrm{PBS}(\mathrm{pH} 7)$ at the surface of GO-CS-SPCS (b) Repeatability performance of the GO-CS-SPCS over 30 successive CV measurements. square root of the scan rate $\left(\mathrm{v}^{1 / 2}\right)$ has also been demonstrated (Figure $5 b$ ), indicating diffusion-controlled reaction kinetics:

$\mathrm{I}_{\mathrm{p}}=3.57 \mathrm{v}^{1 / 2}\left(\mathrm{mV} \mathrm{s}^{-1}\right)-9.1531\left(\mathrm{R}^{2}=0.9833\right)$

The electrooxidation mechanism of $100 \mu \mathrm{M}$ of Tyr at the surface of the GO-CS-SPCS was confirmed by the linear relationship between anodic peak potential $\left(\mathrm{E}_{\mathrm{p}}\right)$ and the logarithm of the applied scan rate $(\ln v)$ (Figure $5 \mathrm{c}$ ), which can be expressed using the regression equation below:

$E_{p}=0.0451 \ln v-0.589 ;\left(R^{2}=0.9662\right)$

The linear plot presented a slope value of 0.0451 , further indicating a diffusion-controlled mechanism in accordance with the kinetic theory of the electrode reaction.

\section{Reproducibility, stability and selectivity}

The repeatability performance of the GO-CS-SPCS was examined in the presence of $100 \mu \mathrm{M}$ Tyr in $0.1 \mathrm{M}$ PBS (pH 7 ), using successive $\mathrm{CV}$ measurements $(\mathrm{N}=30)$, with a scan rate of $100 \mathrm{mV} \mathrm{s}^{-1}$ (Figure 6a). For thirty consecutive measurements using the same sensor, the relative standard deviation (RSD) of the oxidation current responses is $4.02 \%$ (Figure 6b), indicating good repeatability.

To evaluate the selectivity of the GO-CS-SPCS, the disturbing influence of equivalent and increased (10-fold)

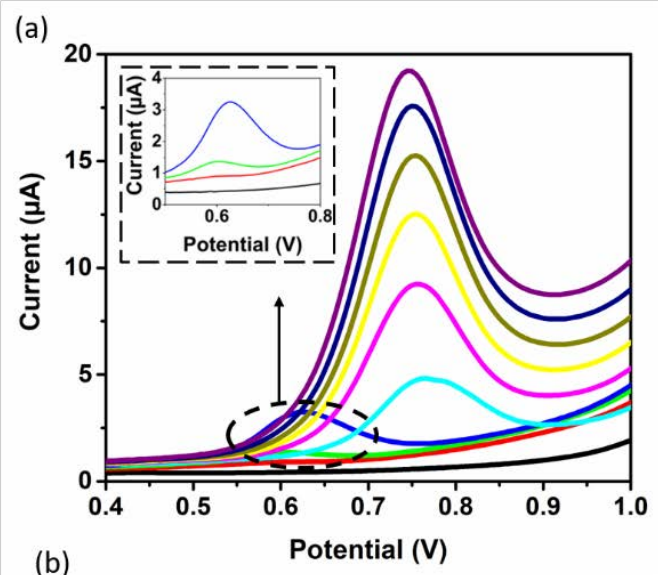

(b)

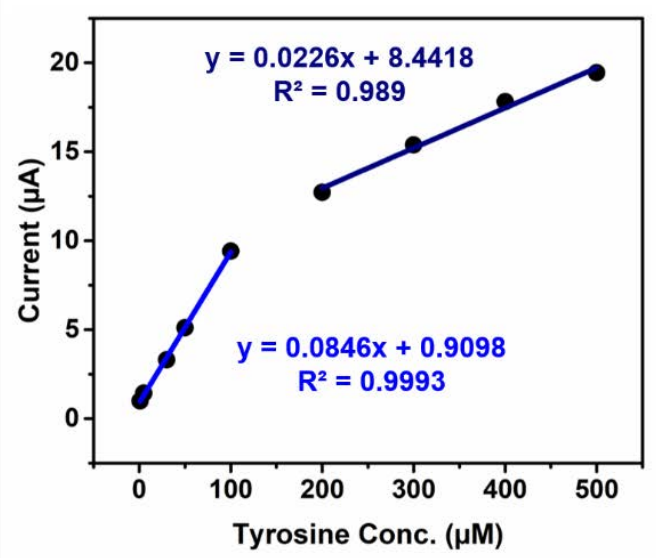

Figure. 7. (a) DPV measurements in the absence and presence of various Tyr concentrations, ranging from $1-500 \mu \mathrm{M}$ in $0.1 \mathrm{M}$ PBS $(\mathrm{pH} 7)$ at the surface of the GO-CS-SPCS, (b) Plot of peak currents $\left(I_{p}\right)$ vs. Tyr concentration. 
TABLE 2

ANALYTICAL PARAMETERS FOR THE DETERMINATION TYR USING GO-CSSPCS

\begin{tabular}{lc}
\hline \hline \multicolumn{1}{c}{ Parameter } \\
\hline Linear dynamic range $(\mu \mathrm{M})$ & $1-100$ \\
Linear regression & $\mathrm{y}=0.0846 \mathrm{x}+0.9098$ \\
Correlation Coefficient & 0.9993 \\
SD of intercept & 0.1504 \\
LOD $(\mu \mathrm{M})$ & 5.8684 \\
LOQ $(\mu \mathrm{M})$ & 21.2856 \\
RSD $(\%)$ & 4.02 \\
Accuracy & $86.43 \pm 30.87$ \\
\hline \hline
\end{tabular}

concentrations of other common amino acids and important biological substances, including lysine, threonine, ascorbic acid, and uric acid, on the determination of Tyr was investigated in 0.1M PBS ( $\mathrm{pH} 7$ ), using DPV measurements. Neither lysine nor threonine significantly interfered with the current response for $100 \mu \mathrm{M}$ Tyr. However, equal or increased (10-fold) concentrations of ascorbic and uric acid may disturb the determination of $100 \mu \mathrm{M}$ Tyr.

\section{E. Electrochemical determination of Tyr using DPV}

The analytical performance of GO-CS-SPCS with increasing Tyr concentration was examined in $0.1 \mathrm{M}$ PBS (pH 7), using DPV. As shown in Figure 7a, well-defined oxidation peaks were observed at the potentials of $500 \mathrm{mV}-1000 \mathrm{mV}$, and the peak current increased as Tyr concentration increased. The plot of peak current versus Tyr concentration is constituted of two linear segments with two different slopes of $0.0846 \mu \mathrm{A} \mu \mathrm{M}^{-1}$ and $0.0226 \mu \mathrm{A} \mu \mathrm{M}^{-1}$, respectively, corresponding to two different analyte ranges $(1-100 \mu \mathrm{M}$ and 200-500 $\mu \mathrm{M}$, respectively) (Figure $7 \mathrm{~b}$ ). The first segment of the plot illustrates a linear relationship between anodic current and Tyr concentration in a range from 1 to $100 \mu \mathrm{M}$, which can be used as a calibration curve for the detection of Tyr. This linear calibration curve presents a correlation coefficient of 0.9993 and is described by the linear regression equation:

$\mathrm{I}_{\mathrm{p}}=0.0846 \mathrm{CTyr}(\mu \mathrm{M})+0.9098\left(\mathrm{R}^{2}=0.9993\right)$

The limit of detection (LOD) was estimated as $5.86 \mu \mathrm{M}$ (Table 2). However, as the concentration of Tyr increased beyond $100 \mu \mathrm{M}$, the sensitivity (slope) of the second linear range decreased:

$\mathrm{I}_{\mathrm{p}}=0.0226 \mathrm{CTyr}(\mu \mathrm{M})+8.4418\left(\mathrm{R}^{2}=0.989\right)$

This decrease in sensitivity is likely due to saturation of the electro-catalytic ability of the GO-CS-SPCS and kinetic limitation $[36,55]$.

\section{CONCLUSION}

This work presents a simple strategy for fabricating an affordable, flexible, and disposable electrochemical sensor that shows promise for Tyr POCT. Unlike current designs, this approach employs easy-to-use fabrication methods, flexible substrates suitable for wearable systems and costeffective, biocompatible, and eco-friendly active materials to produce a sensor suitable for disposable and wearable applications. Owing to the combined effects of GO and CS, including excellent film-forming capability, and increased electrostatic interactions, the GO-CS-SPCS demonstrated good analytical performance and electro-catalytic activity. As the concentration of Tyr increased from 1 to $100 \mu \mathrm{M}$, the sensor showed a linear proportional response, with a correlation coefficient of 0.9993 . The calculated linear range detection limit was $5.86 \mu \mathrm{M}$. Besides, the GO-CS-SPCS showed excellent sensitivity $\left(0.0846 \mu \mathrm{A} \quad \mu \mathrm{M}^{-1}\right)$ and repeatability $(\mathrm{RSD}=4.02 \%)$. The findings of this work, therefore, suggest that the GO-CS-SPCS provides a promising platform for single-use, disposable, and wearable sensors that can potentially be used to investigate a range of biologic conditions, including metabolic or neurodegenerative processes, nutritional management, and wound health, as well as in pharmaceutical, forensic, and food sciences. As the sensor is proposed for wearable healthmonitoring applications, future work will consider the stability of the sensor in real body fluids, such as sweat, urine, wound fluid, and saliva. Due to ease of fabrication and the versatility of this approach, the use of alternative substrates, such as textiles or cloth, could also be explored for additional state of the art wearable technologies. Furthermore, given the simplicity, disability, and flexibility of the GO-CS-SPCS, integration with readout-electronics on a flexible printed circuit board (PCB) will be explored, using an approach similar to that outlined in our previous works [5], for the development of an accurate and affordable biomedical device that can be used for the real-time detection and easy prognosis of abnormal Tyr levels.

\section{ACKNOWLEDGEMENT}

This work was supported in part by Engineering and Physical Sciences Research Council (EPSRC) through Engineering Fellowship for Growth (EP/R029644/1) and the European Commission through AQUASENSE (H2020-MSCA-ITN2018-813680).

\section{REFERENCES}

[1] Y. Yang et al., "A laser-engraved wearable sensor for sensitive detection of uric acid and tyrosine in sweat," Nature Biotech., vol. 38, no. 2, pp. 217-224, 2020 .

[2] Y. Luo, Y. Zhang, L. Lu, and H. Luo, "A flexible CVD graphene platform electrode modified with l-aspartic acid for the simultaneous determination of acetaminophen, epinephrine and tyrosine," $J$. Electroanalytical Chemistry, vol. 856, p. 113737, 2020.

[3] K. Murtada, R. Salghi, A. Ríos, and M. Zougagh, "A sensitive electrochemical sensor based on aluminium doped copper selenide nanoparticles-modified screen printed carbon electrode for determination of L-tyrosine in pharmaceutical samples," J. Electroanalytical Chemistry, vol. 874, p. 114466, 2020.

[4] R. Li et al., "A flexible and physically transient electrochemical sensor for real-time wireless nitric oxide monitoring," Nature comm., vol. 11, no. 1, pp. 1-11, 2020.

[5] M. Bhattacharjee, S. Middya, P. Escobedo, J. Chaudhuri, D. Bandyopadhyay, and R. Dahiya, "Microdroplet based disposable sensor patch for detection of $\alpha$-amylase in human blood serum," Biosensors and Bioelectronics, Vol 165, p. 112333, 2020.

[6] R. Zribi et al., "Exfoliated 2D-MoS2 nanosheets on carbon and gold screen printed electrodes for enzyme-free electrochemical sensing of tyrosine," Sensors and Actuators B: Chemical, vol. 303, p. 127229, 2020.

[7] R. Zribi et al., "Simultaneous and selective determination of dopamine and tyrosine in the presence of uric acid with 2D-MoS2 nanosheets modified screen-printed carbon electrodes," FlatChem, vol. 24, p. $100187,2020$.

[8] J. Li et al., "Electrochemical tyrosine sensor based on a glassy carbon electrode modified with a nanohybrid made from graphene oxide and 
multiwalled carbon nanotubes," Microchimica Acta, vol. 180, no. 1-2, pp. 49-58, 2013.

[9] G.-P. Jin and X.-Q. Lin, "The electrochemical behavior and amperometric determination of tyrosine and tryptophan at a glassy carbon electrode modified with butyrylcholine," Electrochemistry communications, vol. 6, no. 5, pp. 454-460, 2004.

[10] X. Zhang, X. Li, X. Pei, T. Shu, Q. Min, and S. Wang, "Determination of Tyrosine in Artificial Urine Using a Screen-Printed Electrode Modified with tetrathiafulvalene- tetracyanoquinodimethane/ionic Liquid Conductive Gel," Int. J. Electrochem. Sci, vol. 15, pp. 9179-9190, 2020.

[11] A. Parsa, N. Akbarzadeh-Torbati, and H. Beitollahi, "Rapid and Sensitive Electrochemical Monitoring of Tyrosine Using $\mathrm{NiO}$ Nanoparticles Modified Graphite Screen Printed Electrode," Int. J. Electrochem. Sci, vol. 14, pp. 1556-1565, 2019.

[12] J. Wei et al., "A reduced graphene oxide based electrochemical biosensor for tyrosine detection," Nanotechnology, vol. 23, no. 33, p. 335707, 2012.

[13]H. Yang et al., "Simultaneous Determination of Dopamine and Tyrosine Using Poly-glycine/Nafion/MWCNTs Functionalized Plastic-based Miniature Electrochemical Platform," Int. J. Electrochem. Sci, vol. 14, pp. 9584-9595, 2019.

[14]M. K. Hostetter, H. L. Levy, H. S. Winter, G. J. Knight, and J. E. Haddow, "Evidence for liver disease preceding amino acid abnormalities in hereditary tyrosinemia," New England J. Medicine, vol. 308, no. 21, pp. 1265-1267, 1983.

[15]C. Lin, Y.-C. Jair, Y.-C. Chou, P.-S. Chen, and Y.-C. Yeh, "Transcription factor-based biosensor for detection of phenylalanine and tyrosine in urine for diagnosis of phenylketonuria," Analytica chimica acta, vol. 1041, pp. 108-113, 2018.

[16]J. S. Meyer et al., "Neurotransmitter precursor amino acids in the treatment of multi-infarct dementia and Alzheimer's disease," Journal of the American Geriatrics Society, vol. 25, no. 7, pp. 289-298, 1977.

[17]Z. Wei, S. Guo, L. Cheng, T. Li, Y. Zhang, and H. Yang, "Simultaneous Determination of Acetaminophen and Tyrosine Using Screen-printed Electrochemical Sensor Based on MWCNTs-doped Poly (glycine)/Poly (acrylic acid) Conducting Polymers," Int. J. Electrochem. Sci, vol. 14, pp. 6748-6758, 2019

[18]Y. Wang, C. Xiong, H. Qu, W. Chen, A. Ma, and L. Zheng, "Highly sensitive real-time detection of tyrosine based on organic electrochemical transistors with poly-(diallyldimethylammonium chloride), gold nanoparticles and multi-walled carbon nanotubes," J. Electroanalytical Chemistry, vol. 799, pp. 321-326, 2017.

[19]H. Beitollahi and F. Garkani Nejad, "Graphene oxide/ZnO nano composite for sensitive and selective electrochemical sensing of levodopa and tyrosine using modified graphite screen printed electrode," Electroanalysis, vol. 28, no. 9, pp. 2237-2244, 2016.

[20]H.-Y. Chen and Y.-C. Yeh, "Detection of tyrosine and monitoring tyrosinase activity using an enzyme cascade-triggered colorimetric reaction," RSC Advances, vol. 10, no. 50, pp. 29745-29750, 2020.

[21] G. R. Cagnani, G. Ibáñez-Redín, B. Tirich, D. Gonçalves, D. T. Balogh, and O. N. Oliveira Jr, "Fully-printed electrochemical sensors made with flexible screen-printed electrodes modified by roll-to-roll slot-die coating," Biosensors and Bioelectronics, vol. 165, p. 112428, 2020.

[22] M. Bhattacharjee, A. Vilouras, and R. S. Dahiya, "Microdroplet-Based Organic Vapour Sensor on a Disposable GO-Chitosan Flexible Substrate," IEEE Sensors Journal, vol. 20, no. 14, pp. 7494-7502, 2020, doi: 10.1109/JSEN.2020.2992087.

[23]M. Mathew, S. Radhakrishnan, A. Vaidyanathan, B. Chakraborty, and C. S. Rout, "Flexible and wearable electrochemical biosensors based on twodimensional materials: Recent developments," Analytical and Bioanalytical Chemistry, pp. 1-36, 2020.

[24]E. S. Hosseini, S. Dervin, P. Ganguly, and R. Dahiya, "Biodegradable Materials for Sustainable Health Monitoring Devices," ACS Applied Bio Materials, 2020.

[25]R. Dahiya, D. Akinwande, and J. S. Chang, "Flexible Electronic Skin: From Humanoids to Humans [Scanning the Issue]," Proceedings of the IEEE, vol. 107, no. 10, pp. 2011-2015, 2019.

[26] A. Karthika, D. R. Rosaline, S. Inbanathan, A. Suganthi, and M. Rajarajan, "Fabrication of Cupric oxide decorated $\beta$-cyclodextrin nanocomposite solubilized Nafion as a high performance electrochemical sensor for 1-tyrosine detection," J. Physics and Chemistry of Solids, vol. 136, p. 109145, 2020.

[27]L. Manjakkal, S. Dervin, and R. Dahiya, "Flexible potentiometric pH sensors for wearable systems," RSC Advances, vol. 10, no. 15, pp. 8594$8617,2020$.
[28]E. S. Hosseini, L. Manjakkal, D. Shakthivel, and R. Dahiya, "GlycineChitosan-Based Flexible Biodegradable Piezoelectric Pressure Sensor," ACS Applied Materials \& Interfaces, vol. 12, no. 8, pp. 9008-9016, 2020.

[29]R. Dahiya, "E-Skin: From humanoids to humans," Proceedings of the IEEE, vol. 107, no. 2, pp. 247-252, 2019.

[30]W. Navaraj, C. Smith, and R. Dahiya, "Chapter 5 - E-skin and wearable systems for health care," in Wearable Bioelectronics, O. Parlak, A. Salleo, and A. Turner Eds.: Elsevier, 2020, pp. 133-178.

[31] W. Dang, L. Manjakkal, W. T. Navaraj, L. Lorenzelli, V. Vinciguerra, and R. Dahiya, "Stretchable wireless system for sweat pH monitoring," Biosensors and Bioelectronics, vol. 107, pp. 192-202, 2018.

[32]L. Manjakkal, W. Dang, N. Yogeswaran, and R. Dahiya, "Textile-based potentiometric electrochemical $\mathrm{pH}$ sensor for wearable applications," Biosensors, vol. 9, no. 1, p. 14, 2019.

[33] S. Roy et al., "Ultra-sensitive detection of 1-tyrosine using molecularly imprinted electrochemical sensor towards diabetic foot ulcer detection," Electrochemistry Communications, vol. 117, p. 106782, 2020.

[34]A. Khoobi et al., "Sonochemical synthesis of ErVO4/MnWO4 heterostructures: Application as a novel nanostructured surface for electrochemical determination of tyrosine in biological samples," Polyhedron, vol. 177, p. 114302, 2020.

[35]B. Chen, Y. Zhang, L. Lin, H. Chen, and M. Zhao, "Au nanoparticles@ metal organic framework/polythionine loaded with molecularly imprinted polymer sensor: Preparation, characterization, and electrochemical detection of tyrosine," J. Electroanalytical Chemistry, p. 114052, 2020.

[36]C. Kavitha, K. Bramhaiah, and N. S. John, "Low-cost electrochemical detection of l-tyrosine using an $\mathrm{rGO}-\mathrm{Cu}$ modified pencil graphite electrode and its surface orientation on a $\mathrm{Ag}$ electrode using an ex situ spectroelectrochemical method," RSC Advances, vol. 10, no. 39, pp. 22871-22880, 2020.

[37]N. H. Arani, S. M. Ghoreishi, and A. Khoobi, "Increasing the electrochemical system performance using a magnetic nanostructured sensor for simultaneous determination of L-tyrosine and epinephrine," Analytical Methods, vol. 11, no. 9, pp. 1192-1198, 2019.

[38]J. Zou, D. Mao, A. T. S. Wee, and J. Jiang, "Micro/nano-structured ultrathin g-C3N4/Ag nanoparticle hybrids as efficient electrochemical biosensors for L-tyrosine," Applied Surface Science, vol. 467, pp. 608$618,2019$.

[39]L. Syedmoradi, M. Daneshpour, M. Alvandipour, F. A. Gomez, H. Hajghassem, and K. Omidfar, "Point of care testing: The impact of nanotechnology," Biosensors \& Bioelectron., vol. 87, pp. 373-387, 2017.

[40] S. Wang, T. Chinnasamy, M. A. Lifson, F. Inci, and U. Demirci, "Flexible substrate-based devices for point-of-care diagnostics," Trends in biotechnology, vol. 34, no. 11, pp. 909-921, 2016.

[41]M. U. Ahmed et al., "Toward the development of smart and low cost point-of-care biosensors based on screen printed electrodes," Critical reviews in biotechnology, vol. 36, no. 3, pp. 495-505, 2016.

[42] G. Ibáñez-Redín, D. Wilson, D. Gonçalves, and O. Oliveira Jr, "Low-cost screen-printed electrodes based on electrochemically reduced graphene oxide-carbon black nanocomposites for dopamine, epinephrine and paracetamol detection," J. colloid and interface science, vol. 515, pp. 101-108, 2018.

[43]L. Manjakkal, D. Szwagierczak, and R. Dahiya, "Metal oxides based electrochemical $\mathrm{pH}$ sensors: Current progress and future perspectives," Progress in Materials Science, p. 100635, 2019.

[44]W. Dang, V. Vinciguerra, L. Lorenzelli, and R. Dahiya, "Printable stretchable interconnects," Flexible and Printed Electronics, vol. 2, no. 1, p. 013003, 2017.

[45] S. Dervin, A. Ejaz, and R. Dahiya, "A low-cost, disposable GO-CS screen printed carbon electrode for electrochemical detection of tyrosine," in 2020 IEEE Int. Conf. on Flexible and Printable Sensors and Systems (FLEPS), 2020: IEEE, pp. 1-4.

[46]M. A. Kafi, A. Paul, A. Vilouras, E. S. Hosseini, and R. S. Dahiya, "Chitosan-Graphene Oxide-Based Ultra-Thin and Flexible Sensor for Diabetic Wound Monitoring," IEEE Sensors J., vol. 20, no. 13, pp. 67946801, 2019.

[47]M. A. Kafi, A. Paul, A. Vilouras, and R. Dahiya, "Mesoporous chitosan based conformable and resorbable biostrip for dopamine detection," Biosensors and Bioelectronics, vol. 147, p. 111781, 2020.

[48]M. C. Carneiro, F. T. Moreira, R. A. Dutra, R. Fernandes, and M. G. F. Sales, "Homemade 3-carbon electrode system for electrochemical sensing: Application to microRNA detection," Microchemical Journal, vol. 138 , pp. 35-44, 2018. 
[49] S. Dervin, J. Murphy, R. Aviles, S. C. Pillai, and M. Garvey, "An in vitro cytotoxicity assessment of graphene nanosheets on alveolar cells," Applied Surface Science, vol. 434, pp. 1274-1284, 2018.

[50]X. Yang, Y. Tu, L. Li, S. Shang, and X.-m. Tao, "Well-dispersed chitosan/graphene oxide nanocomposites," ACS applied materials \& interfaces, vol. 2, no. 6, pp. 1707-1713, 2010.

[51] C. Qi, L. Zhao, Y. Lin, and D. Wu, "Graphene oxide/chitosan sponge as a novel filtering material for the removal of dye from water," J. colloid and interface science, vol. 517, pp. 18-27, 2018.

[52]D. Han, L. Yan, W. Chen, and W. Li, "Preparation of chitosan/graphene oxide composite film with enhanced mechanical strength in the wet state," Carbohydrate Polymers, vol. 83, no. 2, pp. 653-658, 2011.

[53]K. C. Lai et al., "Ice-templated graphene oxide/chitosan aerogel as an effective adsorbent for sequestration of metanil yellow dye," Bioresource technology, vol. 274, pp. 134-144, 2019.

[54]H. Chen, P. K. Chu, J. He, T. Hu, and M. Yang, "Porous magnetic manganese oxide nanostructures: Synthesis and their application in water treatment," J. colloid and interface sc., vol. 359, no. 1, pp. 68-74, 2011.

[55]S. Ghoreishi, M. Behpour, N. Jafari, and M. Golestaneh, "Electrochemical determination of tyrosine in the presence of dopamine and uric acid at the surface of gold nanoparticles modified carbon paste electrode," J. Chinese Chemical Soc., vol. 59, no. 8, pp. 1015-1020, 2012.

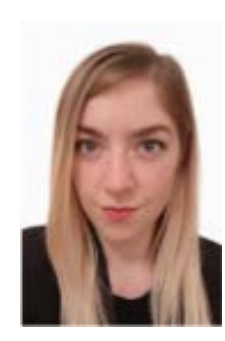

Saoirse Dervin is a Ph.D. candidate in the Nanotechnology and Bio-Engineering research group at the Institute of Technology Sligo, Ireland. She graduated with a B.Sc. (Hons) in Forensic Investigation and Analysis from the Institute of Technology Sligo, Ireland. Saoirse is currently a Marie Curie Early-Stage researcher in the Bendable Electronics and Sensing Technologies (BEST) group at the University of Glasgow. Her current research focuses on the development and use of nano and biomaterials for health and environmental technologies, including biocompatible and bio-friendly sensors, smart scaffolds for skin healing technologies and water quality monitoring. She has authored/co-authored more than 10 research articles and presented in several international and national conferences. She also received the Institute of Chemistry of Ireland Postgraduate Award in 2019.

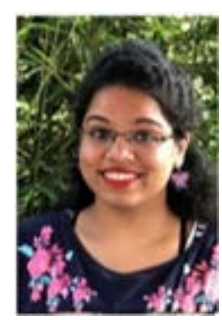

Priyanka Ganguly received her $\mathrm{PhD}$ in Nanotechnology from the Nanotechnology and BioEngineering research group at the Institute of Technology Sligo, Ireland in 2020. She is currently a Marie Curie Early-Stage researcher in the Bendable Electronics and Sensing Technologies (BEST) group at the University of Glasgow. Her research interests include the synthesis and characterization of 2-D nanomaterials, ternary chalcogenides and several metal oxides for various energy and environmental applications. She has authored/co-authored more than 20 research articles and presented in several international and national conferences. She also received the Institute of Chemistry of Ireland Postgraduate Award in 2020.

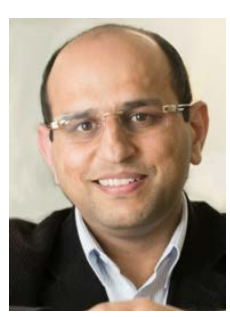

Ravinder Dahiya is Professor of Electronics and Nanoengineering in the University of Glasgow, U.K. He is the leader of Bendable Electronics and Sensing Technologies (BEST) research group. His group conducts fundamental and applied research in flexible and printable electronics, tactile sensing, electronic skin, robotics, and wearable systems. He has authored about 400 research articles, 7 books, and 15 submitted/granted patents. He has led several international projects. He is PresidentElect (2020-21) and Distinguished Lecturer of the IEEE Sensors Council and is serving on the editorial boards of the Scientific Report. $\mathrm{He}$ was also on the editorial boards of IEEE SENSORS JOURNAL (2012-2020) and IEEE TRANSACTIONS ON ROBOTICS (2012-2017). He was the Technical Program co-chair of IEEE Sensors 2017 and IEEE Sensors 2018 and has been General Chair of several conferences including IEEE FLEPS (2019, 2020, 2021), which he founded in 2019. He holds the prestigious EPSRC Fellowship and received in past the Marie Curie and Japanese Monbusho Fellowships. $\mathrm{He}$ has received several awards, including 2016 Microelectronic Engineering Young Investigator Award (Elsevier), 2016 Technical Achievement Award from the IEEE Sensors Council and 9 best paper awards as author/coauthor in International Conferences and Journals. $\mathrm{He}$ is Fellow of IEEE. 